\title{
Case Report \\ Tuberous Sclerosis Complex: case report of a patient with epilepsy and chronic kidney disease
}

Sanchayan Thanancheyan, Nisanthan Selvaratnam, Ghetheeswaran Srivickneswaran, Sivagamasundary Uthayakumaran, Prasath Premkumar

Teaching Hospital, Jaffna, Sri Lanka

Key words: tuberous sclerosis complex, angiolipoma, retinal hamartoma, fibroma, chronic kidney disease

Corresponding Author Sanchayan Thanancheyan, E-mail: <sanchai1990@gmail.com> (D) https://orcid.org/0000-0001-6906-385X

Received: Oct 2020, Accepted Oct 2020, Published: Dec 2020

Competing Interests: Authors have declared that no competing interests exist

(C) Authors. This is an open-access article distributed under a Creative Commons Attribution-Share Alike 4.isO International License (CC BY-SA 4.0), which permits unrestricted use, distribution, and reproduction in any medium, provided the original author and source are attributed and materials are shared under the same license.

\section{Introduction}

Tuberous sclerosis complex (TSC) is an autosomal dominant genetic disorder with a variable clinical presentation and severity. It is a multisystem disease, characterized by hamartomas in various organs, often involving the skin and central nervous system. TSC affects around one in every 6,000 to 10,000 people with equal distribution among sex and ethnic groups. Cutaneous involvement is the most striking finding, enabling early diagnosis and intervention in such cases [1]. However, it has a great phenotypical variability making it difficult to recognize in some instances [2].

\section{Case presentation}

A 44-year-old man on antiepileptics presented to Teaching Hospital, Jaffna (THJ), with progressive facial and bilateral feet swelling and orthopnoea over two months' duration. A diagnosis of epilepsy had been made at the age of eight and he was on antiepileptics since then, He had frequent breakthrough seizures despite antiepileptic treatment. He denied symptoms of myocardial ischaemia and did not have features suggestive of liver disease or hypothyroidism. He was a non-diabetic.

On examination, he was found to have anaemia, facial puffiness, bilateral pitting ankle oedema and lower zone crepitations in both lungs. He had cutaneous lesions comprising forehead fibroma, angiofibroma in the nasolabial folds and hypopigmented lesions on the back of the chest. (Figure 1). 


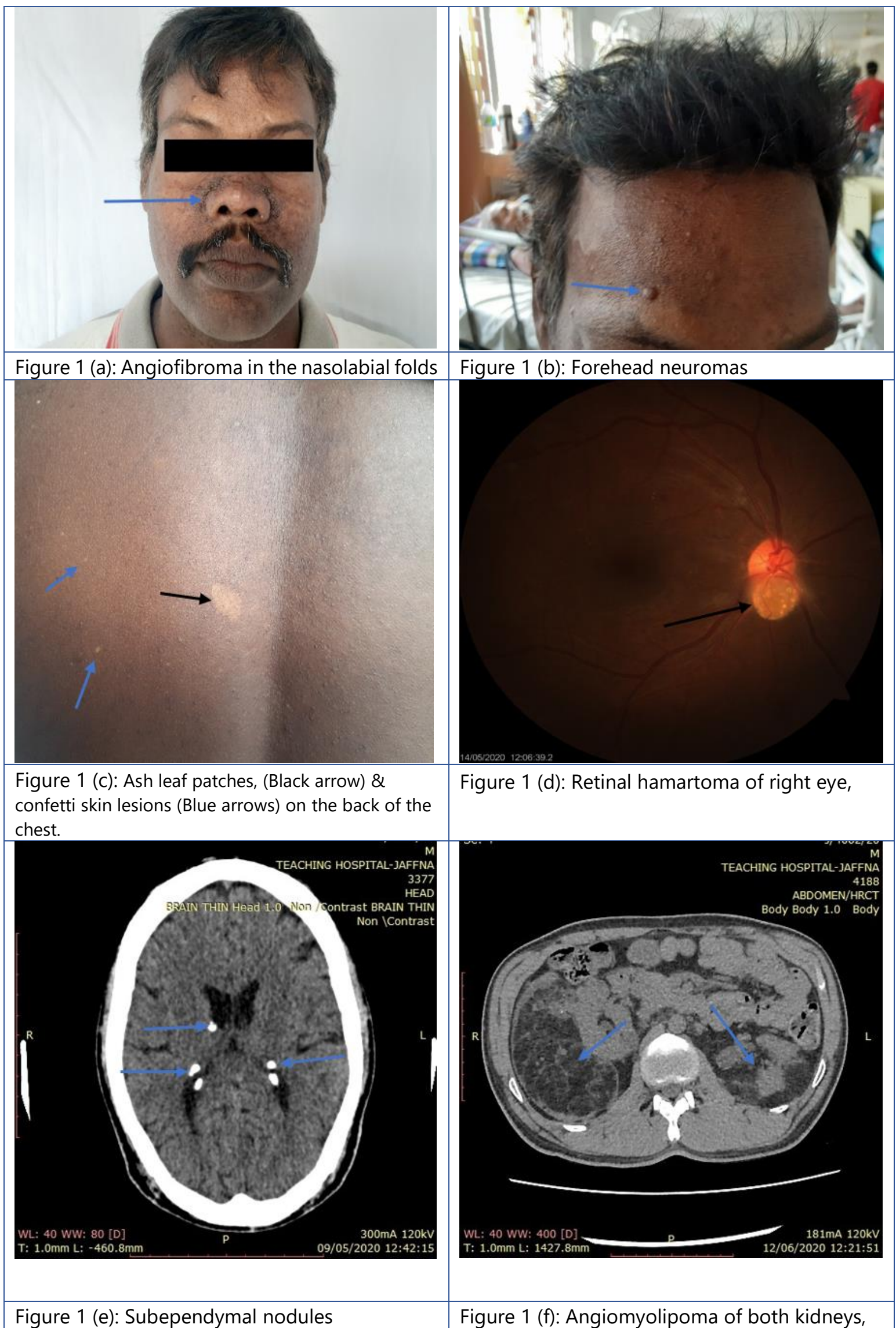


Blood and urine investigations showed chronic kidney disease (CKD) with normocytic normochromic anaemia, elevated blood urea and serum creatinine and hyperkalaemia.

(Table 1)

Table 1: Results of laboratory investigations

\begin{tabular}{|c|c|}
\hline Investigations & Results \\
\hline Full blood count (FBC) & 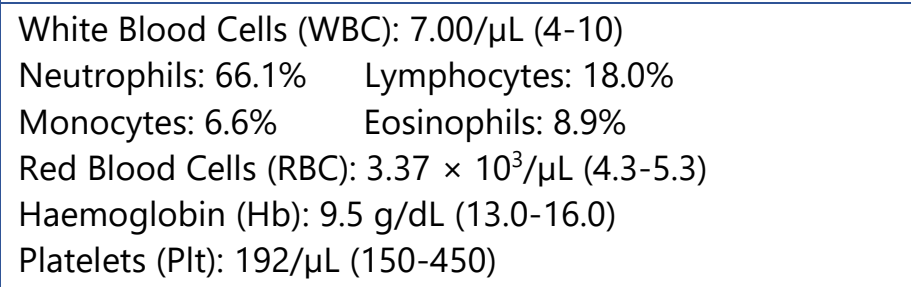 \\
\hline Liver function tests (LFT) & $\begin{array}{l}\text { Alanine Aminotransferase (ALT): } 29 \mathrm{U} / \mathrm{L}(16-63) \\
\text { Aspartate Aminotransferase (AST): } 24 \mathrm{U} / \mathrm{L}(15-37) \\
\text { Alkaline Phosphatase (ALP): } 107 \mathrm{U} / \mathrm{L}(46-116) \\
\text { Total Protein (TP): } 65 \mathrm{~g} / \mathrm{L}(64-82) \\
\text { Albumin: } 28 \mathrm{~g} / \mathrm{L}(34-50) \\
\text { Globulin: } 37 \mathrm{~g} / \mathrm{L}(22-48) \\
\text { Total Bilirubin: } 2.1 \mu \mathrm{mol} / \mathrm{L}(0-17)\end{array}$ \\
\hline Blood urea & $11.7 \mathrm{mmol} / \mathrm{L}(2.5-6.4)$ \\
\hline Serum creatinine & $356 \mu \mathrm{mol} / \mathrm{L}(62-115)$ \\
\hline Erythrocyte sedimentation rate (ESR) & $46 \mathrm{~mm} / 1^{\text {st }}$ hour \\
\hline Serum uric acid & $502 \mu \mathrm{mol} / \mathrm{L}(203-505)$ \\
\hline Serum ferritin & $77.40 \mathrm{ng} / \mathrm{ml}(17.9-464)$ \\
\hline C-reactive protein $(C R P)$ & $0.4 \mathrm{mg} / \mathrm{L}(0-3)$ \\
\hline International normalized ratio (INR) & $0.96(0.8-1.2)$ \\
\hline Thyroid stimulating hormone (TSH) & $4.78(0.465-4.680)$ \\
\hline Blood picture & $\begin{array}{l}\text { Normocytic anaemia compatible with anaemia of renal } \\
\text { disease; Mild eosinophilia probably due to parasite/allergy }\end{array}$ \\
\hline
\end{tabular}

Ultrasound of abdomen showed changes of chronic kidney disease (CKD) in both kidneys. Two-dimensional echocardiogram was normal. He was suspected to have CKD secondary to TSC and was further investigated with dilated eye examination, non-contrast computed tomography (NCCT) of brain, NCCT Abdomen and high-resolution computed tomography (HRCT) of chest which revealed bilateral retinal hamartomas, subependymal nodules (SENs), and bilateral angiomyolipoma (AML) respectively.

A working diagnosis of TSC was established and he was referred to the nephrology and neurology teams for management of complications. Subsequently he was started on oral everolimus and his antiepileptic medications were optimized to carbamazepine PO $300 \mathrm{mg}$ t.i.d, sodium valproate PO 200 mg t.i.d and clobazam PO 10mg b.i.d. Family screening was arranged.

\section{Discussion}

TSC is diagnosed either genetically or clinically. Identification of a pathogenic mutation in TSC1 or TSC2 fulfils the genetic diagnostic criteria. Clinical diagnostic criteria have 11 major clinical features and 06 minor clinical features of which 02 major or one major and two or more minor clinical features are needed for the diagnosis [3]. 
Major clinical features comprise the following; more than 02 hypomelanotic macules of $\geq 5 \mathrm{~mm}$ diameter, more than 02 angiofibromas or fibrous cephalic plaques, at least 02 ungual fibroma, Shagreen patch, multiple retinal hamartomas, cortical dysplasia, subependymal nodules (SENs), subependymal giant cell astrocytoma, cardiac rhabdomyoma, lymphangioleiomyomatosis (LAM) and angiomyolipoma (AML), among which a combination of the last two features alone does not meet the criteria. Minor clinical features consist of confetti skin lesions, more than 02 dental enamel pits, at least 02 intraoral fibromas, retinal achromic patch, multiple renal cysts and nonrenal hamartomas [3]. Our patient satisfied the clinical diagnostic criteria for TCS. (Figure 1)

Renal lesions are common in patients with TSC and angiomyolipoma are the most common among them [3]. Around 35\% of patients with TSC have renal cysts which are usually low in number and uncomplicated except in the polycystic kidney disease (PKD) phenotype in which patients are at risk of complications of autosomal PKD. This is due to joint disruption involving both the TSC2 gene and the PKD1 gene which lies nearby [4]. Lymphangiomas and renal cell carcinoma also occur at smaller frequencies [3]. Renal complications in TSC are an important cause of morbidity and mortality. They are the second leading cause of premature death next to severe intellectual disability [5].

There are two major complications associated with renal AML. One is retroperitoneal haemorrhage originating in the AML called Wunderlich syndrome. AMLs may develop micro and macroaneurysms during enlargement, which can rupture leading to even total nephrectomy. The risk of haemorrhage from renal AML has been found to be around $25 \%$ to $50 \%$ and is significantly higher for females (18\%) than males (8\%) $[4,6]$. The other major complication is CKD due to insidious encroachment of the AML on normal renal tissue. The exact incidence of end-stage renal disease (ESRD) in TSC has not been established. Some studies showed that around 1\% of TSC patients with normal intellect were on dialysis. ESRD also occurs secondary to polycystic kidney disease or the multiple interventions for haemorrhage in patients with TSC. However, even patients with bilateral AML often have normal renal function as kidneys with a large AML burden can still retain renal function [4]. In this patient, there was clinical, biochemical and ultrasonic evidence of CKD stage IV. (Table 1) $A M L$, which are made-up of vascular, smooth muscle and adipose tissue(5) can, albeit rarely, undergo malignant transformation and need close monitoring [4].

Epilepsy is the most frequent presenting feature of TSC and one of the significant causes of morbidity affecting 79 - 90 percent of patients. Not all cortical glioneuronal hamartomas are epileptogenic and patients with TSC and epilepsy may have normal brain magnetic resonance imaging (MRI) [3]. Seizures usually begin in the first year of life. However, patients with TSC can develop seizures in adult life as well [3]. A significant correlation between the number of brain lesions (SENs and cortical tubers) and seizures was not observed [7].

SENs and subependymal giant cell astrocytoma (SEGA) are histologically similar. SENs are benign growths found along the wall of the lateral and third ventricles. Around $80 \%$ of TSC patients appear to have these lesions. SEGAs are found in 5-15\%. SEN, especially near the foramen of Monro, give rise to SEGAs. SEGAs, albeit being slowly growing benign lesions, can result in complications such as obstructive hydrocephalus [5]. Cortical glioneuronal 
hamartomas ("cortical tubers") are similar to SEN in composition and their presence is loosely related to seizure and cerebral functions. There were SENs in this patient's NCCT brain. (Figure 1). MRI brain was attempted in this patient to identify cortical tubers but the image quality was severely hampered by artefacts and the study was abandoned.

Retinal hamartomas share similar histological characteristics to brain tubers. These lesions usually do not cause visual problems. They appear to be a good marker for the disease in young children [5]. This patient had preserved vision despite hamartomas in both eyes.

There was no clinical or HRCT evidence of LAM in this patient. Patients with LAM usually present in middle age with progressive shortness of breath on exertion and recurrent pneumothorax. Lung parenchymal changes are observed in a high number of TSC patients but symptomatic LAM is rare, especially in males [5]. Hamartomas are also found in the endocrine organs. Around $25 \%$ of TSC patients were found to have adrenal AML and thyroid papillary adenoma without thyroid dysfunction has also been reported. Involvement of the pituitary gland, pancreas and gonads has also been reported. These tumours are called nonrenal hamartomas [5]. LAM or endocrine hamartomas were not identified in this patient.

Treatment is required only in a small number of patients with $\mathrm{AML}$ depending on the clinical presentation [8]. Segmental arteries which supply the lesion can be selectively embolized and this is considered as the most effective treatment to prevent complications such as haemorrhage. This technique is usually considered for AMLs that are more than $4 \mathrm{~cm}$ in diameter. Partial nephrectomy is another mode of treatment but its use is hindered by a high rate of complication but, notably, it has a lower incidence of recurrence when compared with selective arterial embolization (SAE). Non-invasive method of treatment of AML consists of pharmacological treatment with everolimus and anti-angiogenic agents and is associated with a lower incidence of complications. Radical nephrectomy is considered only for AMLs with a diameter of more than $8 \mathrm{~cm}$, especially when malignancy is highly suspected and other less invasive methods are contraindicated. This procedure is associated with a high rate of complications [9]. Everolimus was started in this patient as he had CKD secondary to AML.

Seizures in the setting of TSC, especially focal seizures in older children and adults, are treated by oxcarbazepine and carbamazepine while vigabatrin is the drug of choice in children with infantile spasms (8) Levetiracetam and lamotrigine also appear to be effective as adjunct therapy or monotherapy in TSC $[10,11,12]$. Around $60 \%$ of patients with focal epilepsy develop drug resistance [13] and these patients are treated by multiple modalities including a ketogenic diet, vagus nerve stimulation, surgical interventions, everolimus and cannabido [8]l.

Everolimus, an analogue of sirolimus, is an inhibitor of the mammalian target of rapamycin (mTOR). It inhibits serine threonine kinase (mTOR) which controls cell growth and survival, thus helping to suppress tumour growth. Everolimus is licensed for use in patients with TSC to control hamartomatous growth of SEGAs and AML [14].

\section{Conclusion}

TSC, a multisystem disorder, can have a wide spectrum of clinical presentations such as epilepsy and CKD. Even though the striking cutaneous manifestations can help to easily identify the underlying pathology, it is difficult to diagnose TSC in the absence of those 
features, especially if presenting early in the disease. A careful search for lesions is mandatory for early diagnosis and specific treatment of complications.

\section{Acknowledgements}

We are thankful to the house officers - Dr. R. Shangeetha, Dr. K. Tharmiga, Dr. A. Priyavathani, Dr. B. Krishanthi and Dr. T. Kavitha - and nursing staff of Ward 09, THJ for their help in managing this patient. We express our gratitude to Dr. Brammah R Thangarajah, Consultant Nephrologist, THJ and the Department of Neurology, THJ for their contribution in establishing the diagnosis and arranging for further follow up of this patient.

\section{References}

1. Rodrigues DA, Gomes CM, Costa IM. Tuberous sclerosis complex. An Bras Dermatol. 2012;87(2):184-196. https://doi.org/10.1590/S0365-05962012000200001

2. Portocarrero LKL, Quental KN, Samorano LP, Oliveira ZNP, Rivitti-Machado MCDM. Tuberous sclerosis complex: review based on new diagnostic criteria. An Bras Dermatol. 2018;93(3):323-331. https://doi.org/10.1590/abd1806-4841.20186972

3. Randle, S. (2020). Tuberous sclerosis complex: Genetics, clinical features, and diagnosis. In J. F. Dashe (Ed.), UpToDate. Retrieved October 09, 2020, from https://www.uptodate.com/contents/tuberous-sclerosis-complex-genetics-clinicalfeatures-and-diagnosis

4. Bissler JJ, Kingswood JC; Renal angiomyolipomata. Kidney International, Vol. 66 (2004), pp. 924-934 doi.org/10.1111/j.1523-1755.2004.00838.x https://doi.org/10.1111/j.1523-1755.2004.00838.x

5. Krueger DA, Northrup $H$, Tuberous Sclerosis Complex Diagnostic Criteria Update: Recommendations of the 2012 International Tuberous Sclerosis Complex Consensus Conference. Paedtr Neurol 2013; 49 (4), 243-54

6. D.W. Webb, J. Kabala, J.P. Osborne; A population study of renal disease in patients with tuberous sclerosis. Br J Urol, 74 (1994), pp. 151-154. https://doi.org/10.1111/j.1464-410X.1994.tb16577.x

7. Park, S. M., Lee, Y. J., Son, Y. J., Kim, Y. O., \& Woo, Y. J. (2011, December). Clinical Progress of Epilepsy in Children with Tuberous Sclerosis: Prognostic Factors for Seizure Outcome. Chonnam Medical Journal, 47(3), 150-154. Retrieved October 10, 2020 https://doi.org/10.4068/cmj.2011.47.3.150

8. Randle, S. (2020). Tuberous sclerosis complex: Management and prognosis. In J. F. Dashe (Ed.), UpToDate. Retrieved October 10, 2020, from https://www.uptodate.com/contents/tuberous-sclerosis-complex-management-andprognosis

9. Urciuoli, P., D'Orazi, V., Livadoti, G., Foresi, E., Panunzi, A., Anichini, S., Cialini, M., Wlderk, A., Cirelli, C., Colangelo, M., Mongardini, M., \& Custureri, F. (2013, NovemberDecember). Treatment of renal angiomyolipoma: surgery versus angioembolization. II Giornale di chirurgia, 34(11-12), 326-331. Retrieved October 10, 2020

10. Collins, J. J., Tudor, C., Leonard, J. M., Chuck, G., \& Franz, D. N. (2006 , January). Levetiracetam as adjunctive antiepileptic therapy for patients with tuberous sclerosis complex: a retrospective open-label trial. Journal of child neurology, 21(1), 53-57. https://doi.org/10.1177/08830738060210011201 
11. Papacostas, S. S., Papathanasiou, E. S., Myrianthopoulou, P., \& Stylianidou, G. (2007, August). Tuberous sclerosis successfully treated with levetiracetam monotherapy: 18 months of follow-up. Pharmacy world \& science : PWS, 29(4), 350-352. https://doi.org/10.1007/s11096-007-9085-3

12. Franz, D. N., Tudor, C., Leonard, J., Egelhoff, J. C., Byars, A., Valerius, K., \& Sethuraman, G. (2001, July). Lamotrigine therapy of epilepsy in tuberous sclerosis. Epilepsia, 42(7), 935-940. https://doi.org/10.1046/j.1528-1157.2001.042007935.x

13. Jeong, A., Nakagawa, J. A., \& Wong, M. (2017, December). Predictors of Drug-Resistant Epilepsy in Tuberous Sclerosis Complex. Journal of child neurology, 32(14), 1092-1098. https://doi.org/10.1177/0883073817737446

14. MacKeigan, J. P., \& Krueger, D. A. (2015, December). Differentiating the mTOR inhibitors everolimus and sirolimus in the treatment of tuberous sclerosis complex. Neuro-oncology, 17(12), 1550-1559. https://doi.org/10.1093/neuonc/nov152 